\title{
Ventilator-derived carbon dioxide production to assess energy expenditure in critically ill patients: proof of concept
}

Sandra N. Stapel 1,2,3* , Harm-Jan S. de Grooth ${ }^{1,2,3}$, Hoda Alimohamad ${ }^{1,2,3}$, Paul W G Elbers ${ }^{1,2,3}$, Armand R J Girbes ${ }^{1,2,3}$, Peter J M Weijs ${ }^{1,2,3,4}$ and Heleen M. Oudemans-van Straaten ${ }^{1,2,3}$

\begin{abstract}
Introduction: Measurement of energy expenditure (EE) is recommended to guide nutrition in critically ill patients. Availability of a gold standard indirect calorimetry is limited, and continuous measurement is unfeasible. Equations used to predict EE are inaccurate. The purpose of this study was to provide proof of concept that EE can be accurately assessed on the basis of ventilator-derived carbon dioxide production $\left(\mathrm{VCO}_{2}\right)$ and to determine whether this method is more accurate than frequently used predictive equations.

Methods: In 84 mechanically ventilated critically ill patients, we performed 24-h indirect calorimetry to obtain a gold standard EE. Simultaneously, we collected 24-h ventilator-derived $\mathrm{VCO}_{2}$, extracted the respiratory quotient of the administered nutrition, and calculated EE with a rewritten Weir formula. Bias, precision, and accuracy and inaccuracy rates were determined and compared with four predictive equations: the Harris-Benedict, Faisy, and Penn State University equations and the European Society for Clinical Nutrition and Metabolism (ESPEN) guideline equation of $25 \mathrm{kcal} / \mathrm{kg} /$ day.

Results: Mean 24-h indirect calorimetry EE was $1823 \pm 408$ kcal. EE from ventilator-derived $\mathrm{VCO}_{2}$ was accurate (bias $+141 \pm 153 \mathrm{kcal} / 24 \mathrm{~h} ; 7.7 \%$ of gold standard) and more precise than the predictive equations (limits of agreement -166 to $+447 \mathrm{kcal} / 24 \mathrm{~h}$ ). The $10 \%$ and $15 \%$ accuracy rates were $61 \%$ and $76 \%$, respectively, which were significantly higher than those of the Harris-Benedict, Faisy, and ESPEN guideline equations. Large errors of more than $30 \%$ inaccuracy did not occur with EE derived from ventilator-derived $\mathrm{VCO}_{2}$. This $30 \%$ inaccuracy rate was significantly lower than that of the predictive equations.

Conclusions: In critically ill mechanically ventilated patients, assessment of EE based on ventilator-derived $\mathrm{VCO}_{2}$ is accurate and more precise than frequently used predictive equations. It allows for continuous monitoring and is the best alternative to indirect calorimetry.
\end{abstract}

\section{Introduction}

The optimal energy target in the first days of critical illness remains controversial [1-3]. Nonetheless, measurement of energy expenditure (EE) is important to prevent early overfeeding and later underfeeding, as both are associated with increased mortality [4-6]. EE can be accurately assessed with indirect calorimetry, which measures oxygen consumption $\left(\mathrm{VO}_{2}\right)$ and carbon

\footnotetext{
*Correspondence: s.stapel@vumc.nl

'Department of Adult Intensive Care Medicine, VU University Medical Center, De Boelelaan 1117, 1181HV Amsterdam, The Netherlands

${ }^{2}$ Research VUmc Intensive Care (REVIVE), VU University Medical Center, De Boelelaan 1117, 1181HV Amsterdam, The Netherlands

Full list of author information is available at the end of the article
}

dioxide production $\left(\mathrm{VCO}_{2}\right)$ from respiratory gases $[7,8]$. $\mathrm{EE}$ is then calculated using the abbreviated formula published by Weir [9]:

$$
\begin{aligned}
\mathrm{EE} \mathrm{kcal} / \text { day }= & 3.941 \times \mathrm{VO}_{2}(\mathrm{~L} / \mathrm{min})+1.11 \\
& \times \mathrm{VCO}_{2}(\mathrm{~L} / \mathrm{min}) \times 1440
\end{aligned}
$$

Indirect calorimetry is often not available and is resource- and time-consuming. Daily assessment of EE is not feasible but could be important because EE is known to vary widely over time as a result of changing metabolic rate [10-12]. In the absence of indirect calorimetry, numerous predictive equations are used to estimate $\mathrm{EE}$, including the Harris-Benedict equation and the 
European Society for Clinical Nutrition and Metabolism (ESPEN) guideline equation of $25 \mathrm{kcal} / \mathrm{kg} /$ day [13, 14]. These equations are notoriously inaccurate for individual critically ill patients, owing to large disease-, treatment-, and interindividual-related differences in metabolic rate [15-17]. The Penn State University and Faisy equations were especially developed for mechanically ventilated critically ill patients and include temperature and minute ventilation in the calculation of EE [15, 18]. The Penn State University equation is recommended by the Academy of Nutrition and Dietetics when indirect calorimetry is not feasible [19]. Validation studies for both equations are limited.

An alternative method to assess EE in mechanically ventilated critically ill patients could be the use of $\mathrm{VCO}_{2}$ measurements only. This is practical, as most mechanical ventilators provide the option to measure $\mathrm{VCO}_{2}$ continuously. When $\mathrm{VCO}_{2}$ is known, the Weir formula can be used to calculate $\mathrm{VO}_{2}$, assuming the respiratory quotient (RQ), which is the ratio between $\mathrm{VCO}_{2}$ and $\mathrm{VO}_{2}$. Its physiologic range of $0.67-1.2$ depends on the type of the actually metabolized substrate provided that ventilation and acid-base balance are stable [20]. Although the latter vary during critical illness, in prolonged measurement periods metabolic $\mathrm{CO}_{2}$ production equals its excretion. Given these limitations, we hypothesized that EE could be assessed on the basis of ventilator-derived $\mathrm{VCO}_{2}$ using $\mathrm{RQ}$ of the administered nutrition and the rewritten Weir formula.

The aim of this study was to provide proof of concept that EE can be accurately assessed on the basis of ventilator-derived $\mathrm{VCO}_{2}$ and nutritional $\mathrm{RQ}$ and to determine whether this method is more accurate than frequently used predictive equations.

\section{Material and methods}

\section{Study design and setting}

This prospective observational study was conducted in the mixed medical-surgical adult intensive care unit (ICU) of the VU University Medical Center in Amsterdam, The Netherlands. The study was approved by the Medical Ethics Committee of the VU University Medical Center. The need for written informed consent was waived because indirect calorimetry is part of routine care in our ICU and imposes no burden on patients.

\section{Subjects}

Inclusion criteria were age 18 years or older, mechanical ventilation, ICU stay of 3 days or more, and enteral or parenteral nutrition reaching at least two-thirds of calculated nutritional target. According to the standard practice of the unit, the initial nutritional target was an energy delivery as calculated with the revised Harris-Benedict equation [21], adding $20 \%$ for stress and $10 \%$ for activity [22, 23] and protein delivery of $1.2-1.5 \mathrm{~g} / \mathrm{kg}$ preadmission body weight per day [24]. This target was adjusted based on indirect calorimetry measurements. An algorithm was used to determine the optimal nutritional product and amount needed to meet both protein and energy requirements [25]. Patients were excluded if they failed to meet accuracy criteria or safety criteria for indirect calorimetry, being a fraction of inspired oxygen $\left(\mathrm{FiO}_{2}\right)$ greater than 0.6, air leakage through cuff or chest tubes, or a positive end-expiratory pressure (PEEP) greater than $14 \mathrm{cmH}_{2} \mathrm{O}$ (arbitrary limit).

Our patient data management system (PDMS) (MetaVision; iMDsoft, Düsseldorf, Germany) was used to routinely record demographic and clinical data; Acute Physiology and Chronic Health Evaluation (APACHE) II and III scores and APACHE IV predicted mortality [26-28]; diagnosis group; type, amount, and composition of feeding; and ventilation characteristics. Sedation was assessed by using the Ramsay Sedation Scale [29].

\section{Study protocol}

Patient weight and height were recorded upon ICU admission. Preadmission weight and height were obtained, and, if not available, they were measured or estimated by a clinician. Indirect calorimetry was performed for $24 \mathrm{~h}$. Simultaneously, 24-h minute-by-minute ventilator-derived $\mathrm{VCO}_{2}$, which is routinely exported to the PDMS, was recorded. After the first hour of measurement, type and amount of nutrition were adjusted to meet $\mathrm{EE}$ as measured with indirect calorimetry. All macronutrient intake during the study period, including propofol and glucose infusions, were routinely stored in the PDMS.

\section{Methods used to assess energy expenditure Energy expenditure from indirect calorimetry}

Twenty-four-hour indirect calorimetry was performed with a Deltatrac II MBM-200 Metabolic Monitor (Datex, Helsinki, Finland) connected to the ventilator. Before this study, an alcohol-burning test was performed to calibrate the metabolic monitor. Before each 24-h measurement, the metabolic monitor was prepared and calibrated according to the manufacturer's instructions. Artifact suppression was turned on. For each patient, $\mathrm{VCO}_{2}, \mathrm{VO}_{2}, \mathrm{RQ}$, and energy expenditure from indirect calorimetry (EE:Calorimetry) were recorded minute by minute and exported to a computer. For comparison, the mean 24-h value was calculated for each patient.

\section{Energy expenditure from ventilator-derived volume of carbon dioxide and nutritional respiratory quotient}

We use SERVO-i mechanical ventilators (Maquet, Rastatt, Germany) in our ICU. These have mainstream $\mathrm{CO}_{2}$ sensors connected to the airway adapter that measure endtidal $\mathrm{CO}_{2}$. Sensors were calibrated before every study 
period and subsequently at 8-h intervals or more often if necessary. The SERVO-i ventilator calculates $\mathrm{VCO}_{2}$ from the product of $\mathrm{CO}_{2}$ concentration in expiratory air and the expiratory volume $\left(\mathrm{VCO}_{2}=\right.$ volume $\times$ fraction of expired $\mathrm{CO}_{2}$ ).

$\mathrm{VCO}_{2}$ is displayed breath by breath and exported to the PDMS once each minute. For each patient, 24-h minuteby-minute $\mathrm{VCO}_{2}$ values were collected. To calculate energy expenditure from ventilator-derived volume of carbon dioxide and nutritional respiratory quotient (EE: $\left.\mathrm{VCO}_{2}\right)$, the average $24-\mathrm{h} \mathrm{VCO}_{2}(\mathrm{ml} / \mathrm{min})$ was used.

Nutritional RQ was calculated considering 24-h macronutrient delivery, including calories provided by propofol $(1.1 \mathrm{kcal} / \mathrm{ml})$ and glucose $(4 \mathrm{kcal} / \mathrm{g})$. We assumed RQs of 1 for carbohydrates, 0.7 for fat, and 0.8 for protein. Nutritional RQ was calculated from the weighted average RQ for intake during the study period. For example, if the composition of the enteral formula was $16 \%$ protein, $49 \%$ carbohydrates, and $35 \%$ fat, the nutritional RQ was calculated as $0.16 \times 0.8+0.49 \times 1+0.35 \times 0.7=0.86$.

After calculating nutritional RQ for each patient, $\mathrm{EE}: \mathrm{VCO}_{2}$ was subsequently calculated using the following rewritten Weir formula:

$$
\begin{aligned}
E E= & 3.941 \times \mathrm{VCO}_{2}(\mathrm{~L} / \mathrm{min}) \div \text { Nutritional RQ } \\
& +1.11 \times \mathrm{VCO}_{2}(\mathrm{~L} / \mathrm{min}) \times 1440
\end{aligned}
$$

\section{Energy expenditure derived from predictive equations}

EE was calculated using four predictive equations: the Harris-Benedict equation [21], the ESPEN guideline equation [14], the Penn State University 2003b equation [15], and the Faisy equation [18].

Energy expenditure was calculated with the HarrisBenedict equation (EE:HB) as follows:

$$
\begin{aligned}
& \text { men : } 88.362+ 13.397 \times \text { weight }(\mathrm{kg})+4.799 \\
& \times \text { height }(\mathrm{cm})-5.677 \times \operatorname{age}(\mathrm{y}) \\
& \text { women : } 447.593+9.247 \times \text { weight }(\mathrm{kg})+3.098 \\
& \times \operatorname{height}(\mathrm{cm})-4.33 \times \operatorname{age}(\mathrm{y})
\end{aligned}
$$

Energy expenditure was calculated with the European Society for Clinical Nutrition and Metabolism guideline of $25 \mathrm{kcal} / \mathrm{kg} /$ day (EE:Esp25).

Energy expenditure was calculated with the Penn State University 2003b equation (EE:PSU) as follows:

$$
\text { Mifflin-St Jeor } \times 0.96+\mathrm{T} \max \times 167+\mathrm{Ve} \times 31-6212
$$

The Mifflin-St Jeor calculation is as follows [30]:

$$
\begin{aligned}
\text { men : } 10 & \times \text { weight }(\mathrm{kg})+6.25 \times \operatorname{height}(\mathrm{cm})-5 \\
& \times \operatorname{age}(\mathrm{y})+5 \\
\text { women : } 10 & \times \text { weight }(\mathrm{kg})+6.25 \times \operatorname{height}(\mathrm{cm})-5 \\
& \times \operatorname{age}(\mathrm{y})-161
\end{aligned}
$$

Tmax is highest body temperature during the 24-h study period, and Ve is mean minute ventilation during the 24-h study period.

Energy expenditure was calculated with the Faisy equation (EE:Faisy) as follows:

$$
\begin{aligned}
8 & \times \text { weight }(\mathrm{kg})+14 \times \text { height }(\mathrm{cm})+32 \times \mathrm{Ve}(\mathrm{L} / \mathrm{min}) \\
& +94 \times \mathrm{T}-4834
\end{aligned}
$$

Ve is mean minute ventilation during the 24-h study period, and $\mathrm{T}$ is mean temperature during the 24- $\mathrm{h}$ study period.

\section{Endpoints}

The primary endpoint was accuracy of EE: $\mathrm{VCO}_{2}$ using EE:Calorimetry as a gold standard. Secondary endpoints were the accuracy of EE:HB, EE:Esp25, EE:Faisy, and EE:PSU.

\section{Data analysis}

Descriptive data are reported as mean [standard deviation (SD)], median (25th-75th percentile), or number (percentage) as appropriate. Student's $t$ test was used for comparison of paired data. Correlations were calculated using Pearson's test, and strength of correlation was expressed as $r$. The accuracy of the different measurement methods was assessed in accordance with the ISO 5725 standard [31], which describes how accuracy can be defined in terms of bias and precision. Bias is the systematic error as compared with the gold standard (in this case EE:Calorimetry), whereas precision is the random (non-systematic) error of individual measurements. The inaccuracy of a measurement method can thus be due to a large bias (the systematic component), low precision (the random component), or both. Bias was calculated as the mean difference of $\mathrm{EE}: \mathrm{VCO}_{2}$ (or equationbased EEs) and gold standard EE (EE:Calorimetry). EE was considered unbiased if the bias was less than $10 \%$ of the gold standard EE [32]. Precision was quantified as the SD of the bias and the limits of agreement (2 SD). SDs of the different methods were compared using Levene's test for equality of variances. Bland-Altman plots were used to graphically represent bias and limits of agreement [33]. Accuracy was further quantified by accuracy rates, which we defined as the proportion of patients for which the $\mathrm{EE}: \mathrm{VCO}_{2}$ (or equation-based EE) predicted EE within $10 \%$ and $15 \%$ of gold standard EE:Calorimetry. We calculated greater than $25 \%$ and greater than $30 \%$ inaccuracy rates to quantify the occurrence of large errors, as the proportion of patients for which the $\mathrm{EE}: \mathrm{VCO}_{2}$ (or equation-based $\mathrm{EE}$ ) differed by more than $25 \%$ or more than $30 \%$ from gold standard EE:Calorimetry. 
In a post hoc analysis, we calculated for which stress and activity factor the bias of the Harris-Benedict equation was lowest and used this equation in further data analysis (EE:HB15).

IBM SPSS 20 software (IBM, Armonk, NY, USA) was used for statistical analysis. A $p$ value less than 0.05 was considered statistically significant.

\section{Results}

During the study period (20 March to 5 December 2013), 1172 patients were admitted to our ICU. Among them, $163(13.9 \%)$ were mechanically ventilated for more than 3 days with $\mathrm{FiO}_{2} 60 \%$ or less and PEEP 14 $\mathrm{cmH}_{2} \mathrm{O}$ or less. Among these 163 patients, 123 (75\%) received about two-thirds of their nutritional energy target (defined by Harris-Benedict $+30 \%$ ) and 92 of those 123 had no thoracic drains. Of the 92 eligible patients, 84 patients $(91 \%)$ were included (see Fig. 1). The main reason for missed inclusion was absence of a researcher. The included patients' demographic, clinical, and nutritional characteristics are shown in Table 1. Twenty-six patients (31\%) were female. The most prevalent ICU admission diagnoses were post-cardiac arrest, postsurgery, and trauma. Twelve patients (14 \%) had sepsis. The mean APACHE II score was $23.9 \pm 8.4$. Most patients were on pressure support ventilation $(82 \%)$. The mean

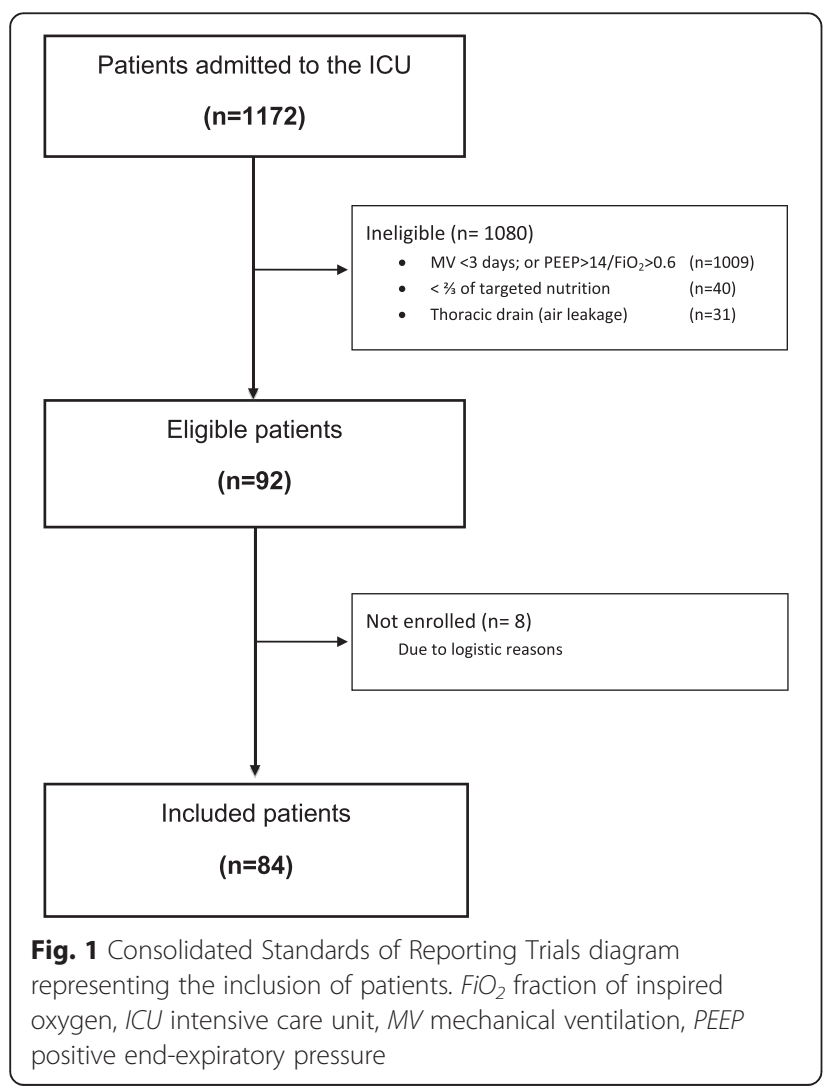

Table 1 Demographic, clinical, and nutritional characteristics of the study population

\begin{tabular}{|c|c|}
\hline Characteristics & Data \\
\hline Number of patients & 84 \\
\hline Male, n (\%) & $58(69)$ \\
\hline Female, n (\%) & $26(31)$ \\
\hline Age, yr (mean \pm SD) & $63.5 \pm 14.9$ \\
\hline Height, cm (mean \pm SD) & $173.7 \pm 7.8$ \\
\hline Weight, kg (mean \pm SD) & $79.1 \pm 16.0$ \\
\hline $\mathrm{BMl}, \mathrm{kg} / \mathrm{m}^{2}$ (mean $\left.\pm \mathrm{SD}\right)$ & $22.7 \pm 4.4$ \\
\hline APACHE II score (mean \pm SD) & $23.9 \pm 8.4$ \\
\hline APACHE III score (mean \pm SD) & $91.0 \pm 34.3$ \\
\hline APACHE IV predicted mortality (mean \pm SD) & $0.47 \pm 0.31$ \\
\hline \multicolumn{2}{|l|}{ ICU admission diagnosis, $\mathrm{n}(\%)$} \\
\hline Trauma & $15(17.9)$ \\
\hline Sepsis & $12(14.3)$ \\
\hline Respiratory insufficiency & $10(11.9)$ \\
\hline Postsurgery & $18(21.4)$ \\
\hline Neurologic & $4(4.8)$ \\
\hline Post-cardiac arrest & $21(25)$ \\
\hline Cardiovascular & $4(4.8)$ \\
\hline Length of ICU stay at time of study, days, median (IQR) & $4.0(3-6)$ \\
\hline Ramsay Sedation Scale score, ${ }^{a}$ median (IQR) & $5(4-6)$ \\
\hline Body temperature, ${ }^{\circ} \mathrm{C}$ (mean $\pm \mathrm{SD}$ ) & $36.8 \pm 0.8$ \\
\hline Heart rate, beats/minute (mean \pm SD) & $91 \pm 20$ \\
\hline MAP, mmHg (mean \pm SD) & $84 \pm 14$ \\
\hline Norepinephrine, n (\%) & $33(39.3)$ \\
\hline $\mathrm{CWH}, \mathrm{n}(\%)$ & $8(9.5)$ \\
\hline Respiratory rate, breaths/min, median (IQR) & $19(15-24)$ \\
\hline Minute volume, L/min (mean \pm SD) & $9.3 \pm 3.2$ \\
\hline Tidal volume, ml (mean \pm SD) & $462 \pm 121$ \\
\hline $\mathrm{PaO}_{2} / \mathrm{FiO}_{2}$ ratio, median (IQR) & $220(180-263)$ \\
\hline PEEP, $\mathrm{cmH}_{2} \mathrm{O}$, median (IQR) & $8(5-10)$ \\
\hline \multicolumn{2}{|l|}{ Mechanical ventilation mode, $\mathrm{n}(\%)$} \\
\hline PS/CPAP & $69(81.4)$ \\
\hline PC & $15(17.9)$ \\
\hline \multicolumn{2}{|l|}{ Type of nutrition, n (\%) } \\
\hline Enteral & $73(86.9)$ \\
\hline Parenteral & $4(4.8)$ \\
\hline Combination enteral and parenteral & $7(8.3)$ \\
\hline Total nutritional intake, kcal/24 h (mean \pm SD) & $1748 \pm 621$ \\
\hline Total macronutrient intake, ${ }^{\mathrm{b}} \mathrm{kcal} / 24 \mathrm{~h}$ (mean \pm SD) & $1835 \pm 627$ \\
\hline Length of mechanical ventilation, days, median (IQR) & $8(6-15)$ \\
\hline Length of stay ICU, days, median (IQR) & $11(7-18)$ \\
\hline
\end{tabular}


Table 1 Demographic, clinical, and nutritional characteristics of the study population (Continued)

\begin{tabular}{ll}
\hline Length of stay hospital, days, median (IQR) & $23(13-45)$ \\
ICU mortality, n (\%) & $29(30.9)$ \\
Hospital mortality, n (\%) & $36(38.3)$ \\
\hline
\end{tabular}

APACHE acute physiology and chronic health evaluation, $B M I$ body mass index CPAP continuous positive airway pressure, $C V V H$ continuous venovenous hemofiltration, ICU intensive care unit IQR interquartile range, MAP mean arterial pressure, $\mathrm{PaO}_{2} / \mathrm{FiO}_{2}$ ratio of partial pressure of arterial oxygen to fraction of inspired oxygen, $P C$ pressure control, PEEP positive end-expiratory pressure, $P S$ pressure support, $S D$ standard deviation

aRamsay Sedation Scale scoring system: 1 = patient anxious and agitated or restless, or both; 2 = patient cooperative, orientated, and tranquil; $3=$ patient responds to commands only; $4=$ brisk response to a light glabellar tap or auditory stimulus; 5 = sluggish response to light glabellar tap or auditory stimulus; $6=$ no response to the stimuli mentioned for scores 4 and 5

${ }^{\mathrm{b}}$ Including intake from intravenous propofol and glucose

total macronutrient intake during the 24-h study period was $1835 \pm 627 \mathrm{kcal}$, including caloric intake from glucose and propofol infusions.

\section{Energy expenditure, $\mathrm{VO}_{2}, \mathrm{VCO}_{2}$, and $\mathrm{RQ}$}

Mean 24-h results for $\mathrm{EE}, \mathrm{VO}_{2}, \mathrm{VCO}_{2}$, and $\mathrm{RQ}$ are presented in Table 2. Mean 24-h EE:Calorimetry was $1823 \pm 408 \mathrm{kcal}$. Mean 24-h EE: $\mathrm{VCO}_{2}$ was $1963 \pm 431 \mathrm{kcal}$,

Table 2 Mean 24-h results of $\mathrm{VCO}_{2}, \mathrm{VO}_{2}, \mathrm{RQ}$, and $\mathrm{EE}$ measurements

\begin{tabular}{lll}
\hline & Mean $\pm \mathrm{SD}$ & $p$ value (vs. calorimetry) \\
\hline $\mathrm{VCO}_{2}$ (ml/min) & & \\
Calorimetry & $225 \pm 47$ & $<0.001$ \\
Ventilator & $240 \pm 52$ & \\
$\mathrm{VO}_{2}$ (ml/min) & & \\
Calorimetry & $265 \pm 59$ & \\
$\mathrm{RQ}$ & & \\
Calorimetry & $0.8592 \pm 0.0473$ & 0.410 \\
Nutrition & $0.8636 \pm 0.0119$ & 0.485 \\
Nutrition & \\
Energy expenditure & $0.8629 \pm 0.0151$ & \\
(kcal/24 h) & & \\
Calorimetry & $1823 \pm 408$ & $<0.001$ \\
VCO -derived & $1963 \pm 431$ & $<0.001$ \\
HB equation & $1576 \pm 257$ & $<0.001$ \\
Esp25 & $1979 \pm 400$ & $<0.001$ \\
Faisy equation & $1999 \pm 269$ & 0.431 \\
PSU & $1801 \pm 314$ & 0.724 \\
HB15 & $1813 \pm 295$ & \\
\hline
\end{tabular}

Calorimetry measured with indirect calorimetry, Esp25 European Society for Clinical Nutrition and Metabolism -guideline equation of $25 \mathrm{kcal} / \mathrm{kg} / \mathrm{day}, \mathrm{HB} 15$ Harris-Benedict equation with $15 \%$ added; PSU Penn State University 2003b equation, $R Q$ respiratory quotient, $S D$ standard deviation, $\mathrm{VCO}_{2}$-derived carbon dioxide production, $\mathrm{VCO}_{2}$-derived from ventilator-derived carbon dioxide production and nutritional respiratory quotient, $\mathrm{VO}_{2}$ oxygen consumption

ancluding macronutrient intake from intravenous propofol and glucose which was significantly higher than EE:Calorimetry $(p<0.001)$ (see Table 2).

\section{Correlation}

EE: $\mathrm{VCO}_{2}$ correlated strongly with EE:Calorimetry $(\mathrm{r}=$ 0.935). The equation-based EEs correlated less strongly and the correlation coefficient was lowest for EE:Esp25 $(r=0.639)$ (see Fig. 2).

\section{Bias (mean difference of $\mathrm{EE}: \mathrm{VCO}_{2}$ and predictive equations with $\mathrm{EE}$ :Calorimetry)}

Bland-Altman plots are shown in Fig. 2. The bias of EE: $\mathrm{VCO}_{2}$ was $+141 \pm 153 \mathrm{kcal} / 24 \mathrm{~h}(7.7 \%$ of EE:Calorimetry). This was significantly lower than the bias of EE:HB $(-246 \pm 263 \mathrm{kcal} / 24 \mathrm{~h}, p<0.001)$, comparable to the bias of EE:Faisy $(+176 \pm 218 \mathrm{kcal} / 24 \mathrm{~h}, p=0.226)$ and EE:Esp25 $(+156 \pm 344 \mathrm{kcal} / 24 \mathrm{~h}, p=0.709)$, but higher than the bias of EE:PSU $(-22 \pm 254 \mathrm{kcal} / 24 \mathrm{~h}, p<0.001)$. In post hoc analysis, we calculated that the bias of the Harris-Benedict equation was lowest with a stress and activity factor of $+15 \%(-10 \pm 257 \mathrm{kcal} / 24 \mathrm{~h})$. See Table 3 for detailed results. The bias of ventilator-derived $\mathrm{VCO}_{2}$ was $14.7 \mathrm{ml} / \mathrm{min}$ ( $6.5 \%$ of $\mathrm{VCO}_{2}:$ Calorimetry). The bias of nutritional RQ was 0.0037 (0.4 \% of RQ:Calorimetry).

\section{Precision}

Limits of agreement were smallest for EE: $\mathrm{VCO}_{2}(-166$ to $+447 \mathrm{kcal} / 24 \mathrm{~h}$ ) The SD of the bias of EE: $\mathrm{VCO}_{2}$ was significantly smaller than that of all equation-based $\mathrm{EE}$ values (see Table 3 and Figs. 2 and 3).

\section{Accuracy and inaccuracy rates}

Less than $10 \%$ and less than $15 \%$ accuracy rates of EE: $\mathrm{VCO}_{2}$ were $61 \%$ and $79 \%$, respectively. These were significantly higher than those of EE:HB, EE:Esp25, and EE:Faisy but not significantly different from EE:PSU and EE:HB15. Less than $25 \%$ and less than $30 \%$ inaccuracy rates of $\mathrm{EE}: \mathrm{VCO}_{2}$ were $2 \%$ and $0 \%$, respectively. The less than $30 \%$ inaccuracy rate of $\mathrm{EE}: \mathrm{VCO}_{2}$ was significantly lower than that of all equation-based $\mathrm{EE}$ values (Table 3 and Fig. 4).

\section{Discussion}

The present prospective observational study in critically ill mechanically ventilated patients provides proof of concept that EE can be accurately calculated from $\mathrm{EE}: \mathrm{VCO}_{2}$. Furthermore, it shows that this method is more precise than frequently used predictive equations. The bias or systematic error of $\mathrm{EE}: \mathrm{VCO}_{2}$ was $141 \mathrm{kcal} /$ $24 \mathrm{~h}$, indicating that $\mathrm{EE}: \mathrm{VCO}_{2}$ as derived from the ventilator systematically overestimates EE compared with gold standard EE:Calorimetry. However, this bias corresponds to a relative error of only $7.7 \%$ of the gold standard, whereas up to $10 \%$ is considered acceptable according to 


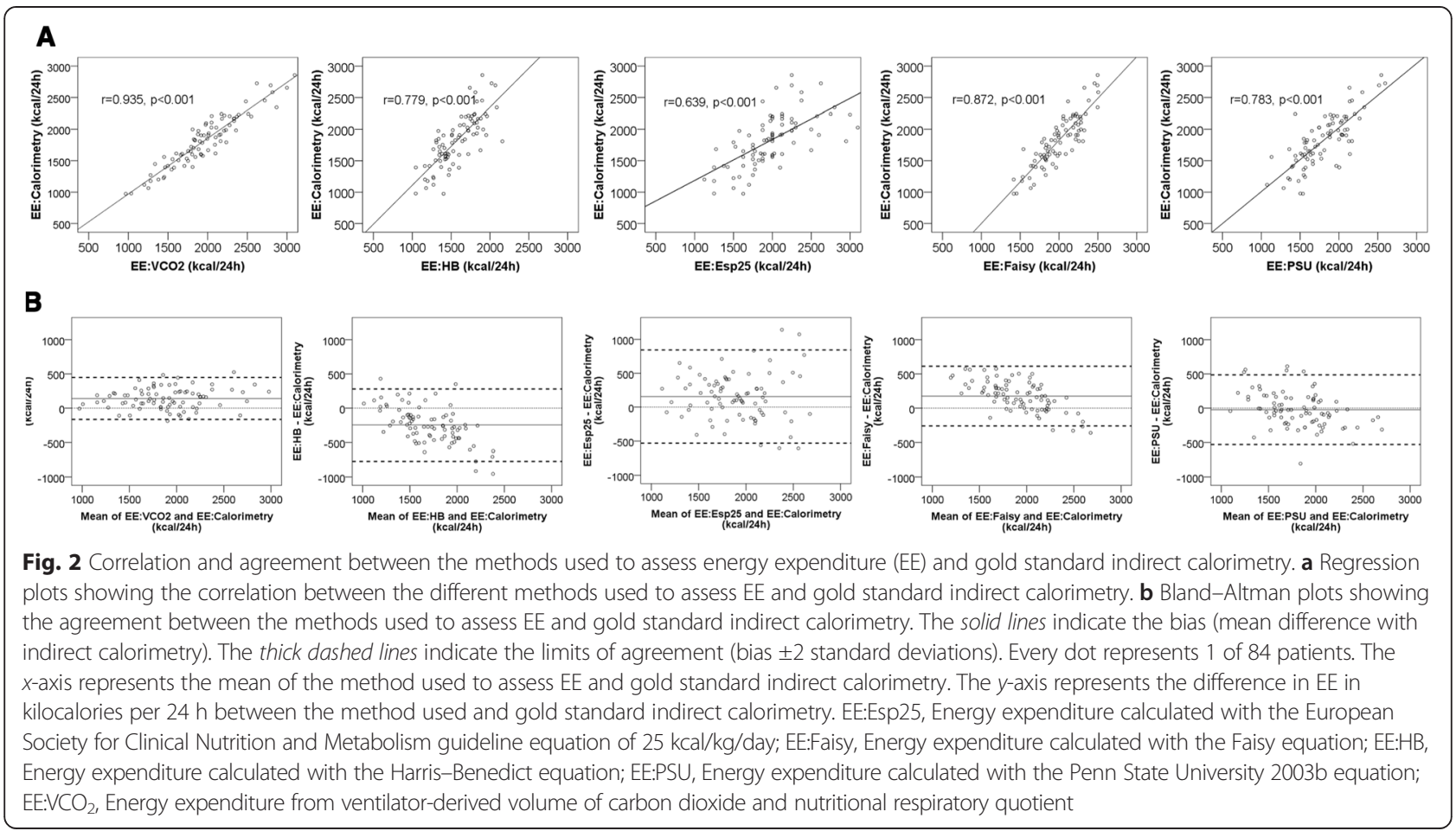

a consensus statement [32]. The precision or random error component of EE: $\mathrm{VCO}_{2}$, expressed as the SD of the bias and compared between methods by using Levene's test, is visualized by the width of the limits of agreement in the Bland-Altman plots and in Fig. 2. The precision of $\mathrm{EE}: \mathrm{VCO}_{2}$ was significantly better than that of the equations.

The accuracy rates of EE: $\mathrm{VCO}_{2}$ were higher than those of all predictive equations, but not significantly so for EE:PSU. However, the inaccuracy of EE:PSU was higher, with greater than $25 \%$ and greater than $30 \%$ inaccuracy rates of $10 \%$ and $6 \%$, respectively, indicating that in more than half of the patients with inaccuracy of greater than $25 \%$, the error was even larger-namely, more than $30 \%$ difference from EE as measured by indirect calorimetry.

High inaccuracy rates were found for $\mathrm{EE}: \mathrm{HB}$ and EE:Esp25, making these equations unacceptable for use in critically ill patients. In all, EE: $\mathrm{VCO}_{2}$ appears to be the most precise equation and EE:PSU and EE:HB15 the most unbiased equations. Despite a better estimation of the mean EE of the study population, the inferior precision of EE:PSU and EE:HB15 led to higher inaccuracy rates, which may result in severe over- or underfeeding in a considerable number of patients. Thus, for the individual patient, $\mathrm{EE}: \mathrm{VCO}_{2}$ performs best.

We further explored the source of the bias of $\mathrm{EE}: \mathrm{VCO}_{2}$, which can be due to inaccuracy of the $\mathrm{VCO}_{2}$ measurement or the RQ estimation. We found an unexpected bias of ventilator-derived $\mathrm{VCO}_{2}$ of $14.7 \mathrm{ml} /$ min (6.5\% of $\mathrm{VCO}_{2}$ :Calorimetry). Assuming an RQ of 0.86 , which is the RQ of most nutritional products, this systematic error accounts for $120 \mathrm{kcal} / 24 \mathrm{~h}$ (i.e., $85 \%$ of the bias of $\mathrm{EE}: \mathrm{VCO}_{2}$ ). We noted the largest differences between ventilator-derived and calorimetry-derived $\mathrm{VCO}_{2}$ in patients with extreme variations in respiratory rate and tidal volume. Rapid and irregular breathing may lead to errors in ventilator-derived $\mathrm{VCO}_{2}$ due to dyssynchrony between the flow and the $\mathrm{CO}_{2}$ measurement. Furthermore, the ventilator exports a single-breath $\mathrm{VCO}_{2}$ value once each minute to the PDMS, which can lead to high variability in patients with irregular breathing. One way of improving the accuracy of the EE: $\mathrm{VCO}_{2}$ method is the development of more accurate $\mathrm{VCO}_{2}$ analyzers in mechanical ventilators, such as by more frequent sampling and data export.

A second source of error and an important limitation of our study is that the actual RQ of the patients was not known. In the present study, we used nutritional RQ. However, during critical illness, RQ is influenced not by actual nutritional intake alone. An unknown and uninhibitable part of energy is derived from endogenous sources, and there are different illness-related degrees of protein synthesis or catabolism, lipogenesis or lipolysis, and gluconeogenesis or glycolysis. Because of the uncertainty of actual RQ when endogenous sources are used for energy, we could not correct RQ if nutritional intake was less than EE. However, our patients received more 
Table 3 Accuracy of the methods used to assess EE, expressed as bias, precision, and accuracy and inaccuracy rates

\begin{tabular}{|c|c|c|c|c|c|c|c|c|}
\hline & \multicolumn{2}{|l|}{ Bias } & \multicolumn{2}{|l|}{ Precision } & \multicolumn{4}{|c|}{ Accuracy quantified } \\
\hline & \multirow{2}{*}{$\begin{array}{l}\text { Mean difference in } \\
\mathrm{kcal} / \mathrm{day}, 95 \% \mathrm{Cl}\end{array}$} & \multirow{2}{*}{$\begin{array}{l}\text { Mean difference } \\
\text { (\% of gold standard EE) }\end{array}$} & \multirow{2}{*}{$\begin{array}{l}\text { SD of bias (Levene's } \\
\text { F-test }^{\mathrm{a}} \text { ) }\end{array}$} & \multirow{2}{*}{$\begin{array}{l}\text { Bland-Altman limits } \\
\text { of agreement }\end{array}$} & \multicolumn{2}{|c|}{ Accuracy rates } & \multicolumn{2}{|c|}{ Inaccuracy rates } \\
\hline & & & & & $<10 \%$ & $<15 \%$ & $>25 \%$ & $>30 \%$ \\
\hline \multicolumn{9}{|l|}{ Method } \\
\hline $\mathrm{EE}: \mathrm{VCO}{ }_{2}^{\mathrm{b}}$ & $+141,+107$ to +174 & $7.7 \%$ & 153 & -166 to +447 & $61 \%$ & $79 \%$ & $2 \%$ & $0 \%$ \\
\hline \multirow[t]{3}{*}{$\mathrm{EE}: \mathrm{HB}^{\mathrm{C}}$} & +246 & $13.5 \%$ & 263 & -722 to +280 & $31 \%$ & $52 \%$ & $13 \%$ & $5 \%$ \\
\hline & -303 to -189 & $p<0.001$ & $(F$ 14.1) & & $p=0.001$ & $p<0.001$ & $p<0.002$ & $p<0.01$ \\
\hline & & & $p<0.001$ & & & & & \\
\hline \multirow[t]{3}{*}{$\mathrm{EE}: \mathrm{Esp} 25^{\mathrm{d}}$} & +156 & $8.6 \%$ & 344 & -531 to +843 & $40 \%$ & $56 \%$ & $25 \%$ & $14 \%$ \\
\hline & +81 to +230 & $p=0.709$ & (F 31.1) & & $p=0.009$ & $p=0.002$ & $p<0.001$ & $p<0.001$ \\
\hline & & & $p<0.001$ & & & & & \\
\hline \multirow[t]{3}{*}{ EE:Faisy ${ }^{\mathrm{e}}$} & +176 & $9.7 \%$ & 218 & -260 to +612 & $45 \%$ & $61 \%$ & $17 \%$ & $12 \%$ \\
\hline & +129 to +233 & $p=0.226$ & $(F 9.0)$ & & $p=0.01$ & $p=0.003$ & $p<0.001$ & $p<0.001$ \\
\hline & & & $p=0.003$ & & & & & \\
\hline \multirow[t]{3}{*}{ EE:PSU ${ }^{f}$} & -22 & $1.2 \%$ & 254 & -529 to +458 & $54 \%$ & $75 \%$ & $10 \%$ & $6 \%$ \\
\hline & -77 to +33 & $p<0.001$ & (F 11.9) & & $p=0.341$ & $p=0.582$ & $p=0.05$ & $p=0.023$ \\
\hline & & & $p<0.001$ & & & & & \\
\hline \multicolumn{9}{|c|}{ Post hoc calculation } \\
\hline \multirow[t]{3}{*}{ EE:HB159 } & -10 & $0.5 \%$ & 257 & -524 to +504 & $55 \%$ & $71 \%$ & $10 \%$ & $6 \%$ \\
\hline & -66 to +46 & $p<0.001$ & (F 12.3) & & $p=0.435$ & $p=0.285$ & $p=0.05$ & $p=0.023$ \\
\hline & & & $p<0.001$ & & & & & \\
\hline
\end{tabular}

EE energy expenditure, EE:Esp25 energy expenditure calculated with the European Society for Clinical Nutrition and Metabolism guideline equation of $25 \mathrm{kcal} / \mathrm{kg} /$ day, EE:Faisy energy expenditure calculated with the Faisy equation, EE:HB15 energy expenditure calculated with the Harris-Benedict equation with $15 \%$ added, EE:PSU energy expenditure calculated with the Penn State University $2003 \mathrm{~b}$ equation, EE:VCO ${ }_{2}$ energy expenditure from ventilator-derived volume of carbon dioxide and nutritional respiratory quotient, $H B$ Harris-Benedict equation

Less than $10 \%$ and less than $15 \%$ accuracy rates represent the proportion of patients for which EE: $\mathrm{VCO}_{2}$ (or equation-based EE) predicted EE within $10 \%$ and within $15 \%$, respectively, of gold standard

EE:Calorimetry. Greater than $25 \%$ and greater than $30 \%$ inaccuracy rates represent the proportion of patients for whom EE: $\mathrm{VCO}_{2}$ (or equation-based EE) differed by more than $25 \%$ and more than $30 \%$, respectively, from gold standard EE:Calorimetry

$F$-test and $p$ value reflect the comparison of the variance of the mean difference of $\mathrm{EE}: \mathrm{VCO}_{2}$ and $\mathrm{EE}$ from equations. The higher the $F$-value, the higher the difference of the variances. $p<0.05$ indicates that the

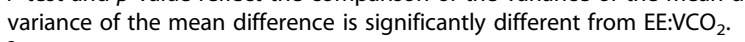

Bias: ${ }^{b}$ vs. ${ }^{c} p<0.001 ;{ }^{b}$ vs. ${ }^{d} p=0.709 ;{ }^{b}$ vs. ${ }^{f} p=<0.001 ;{ }^{b}$ vs. ${ }^{e} p<0.001 ;{ }^{b}$ vs. ${ }^{g} p=0.226 ;{ }^{c}$ vs. ${ }^{d} p<0.001 ;{ }^{c}$ vs. ${ }^{f} p<0.001 ;{ }^{c}$ vs. ${ }^{e} p<0.001 ;{ }^{c}$ vs. ${ }^{g} p<0.001 ;{ }^{d}$ vs. ${ }^{f} p=0.001 ;{ }^{d}$ vs. ${ }^{e} p<0.001 ;{ }^{d}$ vs. ${ }^{g} p=0.652 ;{ }^{f}$ vs. ${ }^{e} p=0.762 ;$ e vs. ${ }^{g} p<0.001$ 


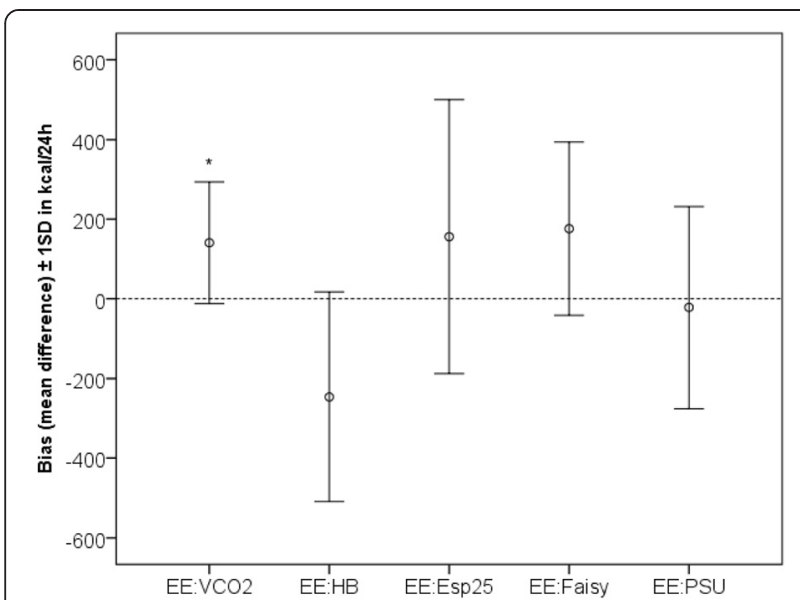

Fig. 3 Bias and precision of the methods used to assess energy expenditure (EE). The $x$-axis shows the different methods used to assess EE. The $y$-axis represents the bias (mean difference with gold standard indirect calorimetry) and the precision ( \pm 1 standard deviation) in kilocalories per day. *Variance of the bias significantly smaller than that of the predictive equations. EE:Esp25, Energy expenditure calculated with the European Society for Clinical Nutrition and Metabolism guideline equation of $25 \mathrm{kcal} / \mathrm{kg} /$ day; EE:Faisy, Energy expenditure calculated with the Faisy equation; EE:HB, Energy expenditure calculated with the Harris-Benedict equation; EE:PSU, Energy expenditure calculated with the Penn State University 2003b equation; $\mathrm{EE}: \mathrm{VCO}_{2}$, Energy expenditure from ventilator-derived volume of carbon dioxide and nutritional respiratory quotient

than two-thirds of actual EE, and this is the time point when measurement of EE becomes relevant. RQ is also influenced by periods of hypo- and hyperventilation (e.g., induced by stress or sedation or in respiratory compensation for metabolic acidosis or alkalosis). This will temporarily modulate $\mathrm{VCO}_{2}$ [34]; however, over $24 \mathrm{~h}$, mean $\mathrm{VCO}_{2}$ reflects $\mathrm{CO}_{2}$ produced by metabolism. Although nutritional RQ did indeed not correlate with measured RQ:Calorimetry, only $15 \%$ of the bias of $\mathrm{EE}: \mathrm{VCO}_{2}$ was attributable to the difference between nutritional RQ and RQ:Calorimetry.

In our study, additional calories provided during the study period by glucose and propofol were taken into account. With a single exception in a patient who received large amounts of glucose $40 \%$, these additional calories did not substantially change nutritional RQ and subsequently EE: $\mathrm{VCO}_{2}$.

Mehta et al. tested the accuracy of a $\mathrm{VCO}_{2}$ based equation to calculate EE in critically ill children [35]. Metabolic data from mechanically ventilated children was used to derive this equation. The equation was then applied to a second dataset of critically ill children to test accuracy. They found superiority of the simplified equation over standard equations. These findings further strengthen the concept of using $\mathrm{VCO}_{2}$ measurement instead of estimating equations to calculate $\mathrm{EE}$ in critically ill adults and children. It should be noted, however, that the $\mathrm{VCO}_{2}$ in the Mehta study was not independently measured; it was derived from the metabolic monitor. Thus, a direct comparison between EE:Calorimetry and a ventilator-derived or separate module-derived $\mathrm{EE}: \mathrm{VCO}_{2}$ was not performed. Mehta et al. mentioned this as a limitation of their study. Also, measurement periods were relatively short. We were able to perform simultaneous $24-\mathrm{h} \mathrm{VCO}_{2}$ and indirect calorimetric measurements in a large and representative population of ICU patients ventilated for more than 3 days, providing information on real-time total EE.
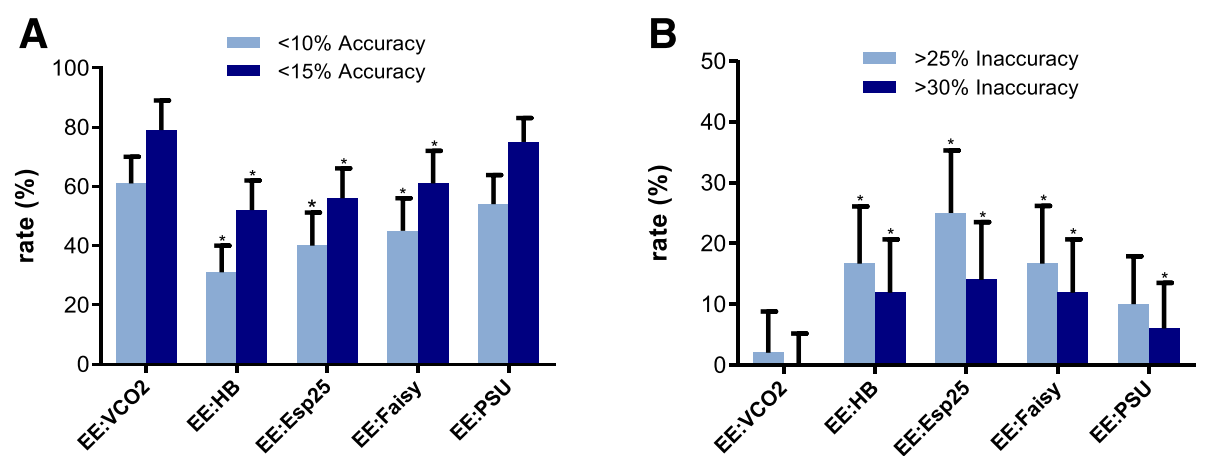

Fig. 4 Accuracy and inaccuracy of the different methods quantified in less than $10 \%$ and less than $15 \%$ accuracy rates and greater than $25 \%$ and greater than $30 \%$ inaccuracy rates. a Less than $10 \%$ and less than $15 \%$ accuracy rates were defined as the proportion of patients for whom energy expenditure (EE) was predicted within $10 \%$ and within $15 \%$ of gold standard EE:Calorimetry. b Greater than $25 \%$ and greater than $30 \%$ inaccuracy rates were defined as the proportion of patients for whom EE differed by more than $25 \%$ and more than $30 \%$ from gold standard EE:Calorimetry. The $x$-axis shows the different methods used to assess EE. The $y$-axis represents the accuracy rates or inaccuracy rates in percentages. The error bars reflect upper bounds of $95 \%$ confidence intervals. *Significantly different from EE: $\mathrm{VCO}_{2}$ ( $p$ values are shown in Table 3). EE:Esp25, Energy expenditure calculated with the European Society for Clinical Nutrition and Metabolism guideline equation of $25 \mathrm{kcal} / \mathrm{kg} /$ day; EE:Faisy, Energy expenditure calculated with the Faisy equation; EE:HB, Energy expenditure calculated with the Harris-Benedict equation; EE:PSU, Energy expenditure calculated with the Penn State University 2003b equation; $\mathrm{EE}_{\mathrm{V}} \mathrm{CO}_{2}$, Energy expenditure from ventilator-derived volume of carbon dioxide and nutritional respiratory quotient 
Indirect calorimetry remains the gold standard. However, the most validated system, the Deltatrac, is no longer being manufactured. While we await new, accurate, affordable metabolic monitors, $\mathrm{EE}: \mathrm{VCO}_{2}$ could be of great benefit for ICUs that do not have indirect calorimetry available. The method can also be used to monitor fluctuations in $\mathrm{EE}$ over time and to identify patients at risk for being over- or underfed. EE: $\mathrm{VCO}_{2}$ allows for daily adjustment of nutrition in ventilated patients. This may be important because metabolic rate and associated energy requirements vary widely during the day and during the course of disease [11, 12, 36, 37]. Another major advantage of $\mathrm{EE}: \mathrm{VCO}_{2}$ is that the calculation of $\mathrm{EE}$ is independent of body length and weight, thereby reducing error.

We are aware of the fact that not all ICUs have mechanical ventilators that measure $\mathrm{VCO}_{2}$ continuously. Most modern ventilators do have this option available and cost less than a metabolic monitor. Of note, the present validation was performed with one type of mechanical ventilator. We do not know the accuracy of $\mathrm{VCO}_{2}$ measurements with other ventilators.

We excluded patients with $\mathrm{FiO}_{2}$ exceeding 0.6 for reliability reasons and patients with PEEP above $14 \mathrm{cmH}_{2} \mathrm{O}$ because of risks associated with disconnection when connecting the indirect calorimeter to the ventilator. Therefore, our method was not validated in this population. Nonetheless, we suppose that $\mathrm{EE}: \mathrm{VCO}_{2}$ is reliable in all mechanically ventilated patients, regardless of ventilator settings, provided that air leakage is not present.

The most important message of this study is that EE (kcal/day) can be calculated at the bedside as $8.19 \times \mathrm{VCO}_{2}(\mathrm{ml} / \mathrm{min})$. This equation is derived from the rewritten Weir formula using an RQ of 0.86 , which is the RQ of most nutritional products, and after converting liters per minute to milliliters per minute.

\section{Conclusions}

In critically ill mechanically ventilated adult patients, the assessment of EE from ventilator-derived $\mathrm{VCO}_{2}$ is accurate and more precise than frequently used predictive equations. It allows for continuous monitoring and provides the best alternative to gold standard indirect calorimetry. Future studies are necessary to improve accuracy of the $\mathrm{VCO}_{2}$ measurement, to detect sources of error, and to investigate whether daily adjustment of nutrition based on ventilator-derived EE improves the outcome of ICU patients.

\section{Key messages}

- EE from ventilator-derived $\mathrm{VCO}_{2}$ is accurate and more precise than predictive equations.
- This method allows for continuous monitoring and is the best alternative to indirect calorimetry.

- $\mathrm{EE}(\mathrm{kcal} /$ day) can be calculated at the bedside as $8.19 \times \mathrm{VCO}_{2}(\mathrm{ml} / \mathrm{min})$.

\section{Abbreviations}

APACHE: Acute Physiology and Chronic Health Evaluation; BMI: Body mass index; CPAP: Continuous positive airway pressure; $\mathrm{CWH}$ : continuous venovenous hemofiltration, EE, Energy expenditure; EE:Esp25: Energy expenditure calculated with the European Society for Clinical Nutrition and Metabolism guideline equation of $25 \mathrm{kcal} / \mathrm{kg} /$ day; EE:Faisy: Energy expenditure calculated with the Faisy equation; EE:HB: Energy expenditure calculated with the Harris-Benedict equation; EE:PSU: Energy expenditure calculated with the Penn State University 2003b equation; $\mathrm{EE}: \mathrm{VCO}_{2}$ : Energy expenditure from ventilator-derived volume of carbon dioxide and nutritional respiratory quotient; ESPEN: European Society for Clinical Nutrition and Metabolism; $\mathrm{FiO}_{2}$ : Fraction of inspired oxygen; ICU: Intensive care unit; IQR: Interquartile range; MAP: mean arterial pressure; $\mathrm{PaO}_{2}$ : Partial pressure of arterial oxygen; PC: Pressure control; PDMS: Patient data management system; PEEP: Positive end-expiratory pressure; PS: Pressure support; RQ: Respiratory quotient; SD: Standard deviation; T: Mean temperature during the 24-h study period; Tmax: Maximum body temperature during the 24-h study period; $\mathrm{VCO}_{2}$ : carbon dioxide production; Ve: Mean minute ventilation during the 24-h study period; $\mathrm{VO}_{2}$ : oxygen consumption.

\section{Competing interests}

The authors declare that they have no competing interests.

\section{Authors' contributions}

SNS, ARJG, PJMW, PWGE, and HMOvS designed the study. SNS and HA obtained the data. SNS, HJSdG, HMOvS, and PJMW analyzed the data. HMOvS had primary responsibility for final content. All authors contributed to the drafting of the manuscript. All authors read and approved the final manuscript.

\section{Acknowledgements}

We thank Ronald Driessen of the Department of Adult Intensive Care Medicine at VU University Medical Center for his contribution.

\section{Author details}

'Department of Adult Intensive Care Medicine, VU University Medical Center, De Boelelaan 1117, 1181 HV Amsterdam, The Netherlands. ${ }^{2}$ Research VUmc Intensive Care (REVIVE), VU University Medical Center, De Boelelaan 1117. 1181HV Amsterdam, The Netherlands. ${ }^{3}$ Institute of Cardiovascular Research (ICaR-VU), VU University Medical Center, De Boelelaan 1117, 1181HV Amsterdam, The Netherlands. ${ }^{4}$ Nutrition and Dietetics, Department of Internal Medicine, VU University Medical Center, De Boelelaan 1117, 1181HV Amsterdam, The Netherlands.

Received: 3 August 2015 Accepted: 29 September 2015

Published online: 22 October 2015

\section{References}

1. Casaer MP, Mesotten D, Hermans G, Wouters PJ, Schetz M, Meyfroidt G, et al. Early versus late parenteral nutrition in critically ill adults. N Engl J Med. 2011;365:506-17.

2. Rice TW, Mogan S, Hays MA, Bernard GR, Jensen GL, Wheeler AP. Randomized trial of initial trophic versus full-energy enteral nutrition in mechanically ventilated patients with acute respiratory failure. Crit Care Med. 2011;39:967-74.

3. Singer P, Anbar R, Cohen J, Shapiro H, Shalita-Chesner M, Lev S, et al. The tight calorie control study (TICACOS): a prospective, randomized, controlled pilot study of nutritional support in critically ill patients. Intensive Care Med. 2011;37:601-9.

4. Villet S, Chiolero RL, Bollmann MD, Revelly JP, Cayeux RNM, Delarue J, et al. Negative impact of hypocaloric feeding and energy balance on clinical outcome in ICU patients. Clin Nutr. 2005;24:502-9.

5. Weijs PJM, Looijaard GPM, Beishuizen A, Girbes ARJ, Oudemans-van Straaten HM. Early high protein intake is associated with low mortality and energy overfeeding with high mortality in non-septic mechanically ventilated critically ill patients. Crit Care. 2014;18:701. 
6. Singer $\mathrm{P}$, Pichard $\mathrm{C}$, Heidegger $\mathrm{CP}$, Wernerman J. Considering energy deficit in the intensive care unit. Curr Opin Clin Nutr Metab Care. 2010;13:170-6.

7. Cooney RN, Frankenfield DC. Determining energy needs in critically ill patients: equations or indirect calorimeters. Curr Opin Crit Care. 2012;18:174-7

8. Branson RD, Johannigman JA. The measurement of energy expenditure Nutr Clin Pract. 2004;19:622-36.

9. Weir JB. New methods for calculating metabolic rate with special reference to protein metabolism. Nutrition. 1990;6:213-21.

10. McClave SA, Martindale RG, Kiraly L. The use of indirect calorimetry in the intensive care unit. Curr Opin Clin Nutr Metab Care. 2013;16:202-8.

11. Preiser JC, Ichai C, Orban JC, Groeneveld AB. Metabolic response to the stress of critical illness. Br J Anaesth. 2014;113:945-54.

12. Berger $M M$, Pichard $C$. Best timing for energy provision during critical illness. Crit Care. 2012;16:215.

13. Harris JA, Benedict FG. A biometric study of human basal metabolism. Proc Natl Acad Sci USA. 1918:4:370-3.

14. Kreymann KG, Berger MM, Deutz NE, Hiesmayr M, Jolliet P, Kazandjiev G, et al. ESPEN guidelines on enteral nutrition: intensive care. Clin Nutr. 2006;25:210-23.

15. Frankenfield DC, Coleman A, Alam S, Cooney RN. Analysis of estimation methods for resting metabolic rate in critically ill adults. J Parenter Enteral Nutr. 2009;33:27-36.

16. Weijs PJ. Validity of predictive equations for resting energy expenditure in US and Dutch overweight and obese class I and II adults aged 18-65 y. Am J Clin Nutr. 2008:88:959-70.

17. Walker RN, Heuberger RA. Predictive equations for energy needs for the critically ill. Respir Care. 2009;54:509-21.

18. Faisy C, Guerot E, Diehl J, Labrousse J, Fagon J. Assessment of resting energy expenditure in mechanically ventilated patients. Am J Clin Nutr. 2003;78:241-9.

19. Academy of Nutrition and Dietetics. Critical illness evidence-based nutrition practice guideline. Chicago: Author; 2012. http://www.guideline.gov/ content.aspx?id=39404. Accessed 15 Oct 2015.

20. Haugen HA, Chan LN, Li F. Indirect calorimetry: a practical guide for clinicians. Nutr Clin Pract. 2007:22:377-88.

21. Roza AM, Shizgal HM. The Harris Benedict equation re-evaluated: resting energy requirements and the body cell mass. Am J Clin Nutr. 1984;40:168-82.

22. Alexander E, Susla GM, Burstein AH, Brown DT, Ognibene FP. Retrospective evaluation of commonly used equations to predict energy expenditure in mechanically ventilated, critically ill patients. Pharmacotherapy. 2004;24:1659-67.

23. van Lanschot JJ, Feenstra BW, Vermeij CG, Bruining HA. Calculation versus measurement of total energy expenditure. Crit Care Med. 1986;14:981-5.

24. Sauerwein HP, Strack van Schijndel RJ. Perspective: How to evaluate studies on peri-operative nutrition? Considerations about the definition of optimal nutrition for patients and its key role in the comparison of the results of studies on nutritional intervention. Clin Nutr. 2007;26:154-8.

25. van Strack van Schijndel RJM, Weijs PJM, Sauerwein HP, de Groot SDW, Beishuizen A, Girbes ARJ. An algorithm for balanced protein/energy provision in critically ill mechanically ventilated patients. E Spen Eur E J Clin Nutr Metab. 2007;2:69-74.

26. Knaus WA, Draper EA, Wagner DP, Zimmerman JE. APACHE II: a severity of disease classification system. Crit Care Med. 1985;13:818-29.

27. Knaus WA, Wagner DP, Draper EA, Zimmerman JE, Bergner M, Bastos PG, et al. The APACHE III prognostic system: risk prediction of hospital mortality for critically ill hospitalized adults. Chest. 1991;100:1619-936.

28. Zimmerman JE, Kramer AA, McNair DS, Malila FM. Acute Physiology and Chronic Health Evaluation (APACHE) IV: hospital mortality assessment for today's critically ill patients. Crit Care Med. 2006;34:1297-310.

29. Ramsay MAE, Savege TM, Simpson BRJ, Goodwin R. Controlled sedation with alphaxalone-alphadolone. Br Med J. 1974;2:656-9.

30. Mifflin MD, St Jeor ST, Hill LA, Scott BJ, Daugherty SA, Koh YO. A new predictive equation for resting energy expenditure in healthy individuals. Am J Clin Nutr. 1990:51:241-7.

31. International Organization for Standardization (ISO). Accuracy (trueness and precision) of measurement methods and results. Part 1: general principles and definitions. ISO 5725-1:1994. https://www.iso.org/obp/ui/ \#iso:std:iso:5725:-1:ed-1:en. Accessed 15 Oct 2015.
32. Frankenfield D, Hise M, Malone A, Russell M, Gradwell E, Compher C. Prediction of resting metabolic rate in critically ill adult patients: results of a systematic review of the evidence. J Am Diet Assoc. 2007;107:1552-61.

33. Bland JM, Altman DG. Statistical methods for assessing agreement between two methods of clinical measurement. Lancet. 1986;1:307-10.

34. McClave SA, Lowen CC, Kleber MJ, McConnell JW, Jung LY, Goldsmith $\perp$. Clinical use of the respiratory quotient obtained from indirect calorimetry. J Parenter Enteral Nutr. 2003;27:21-6.

35. Mehta NM, Smallwood CD, Joosten KFM, Hulst JM, Tasker RC, Duggan CP. Accuracy of a simplified equation for energy expenditure based on bedside volumetric carbon dioxide elimination measurement - a two-center study. Clin Nutr. 2015;34:151-5.

36. Fraipont V, Preiser JC. Energy estimation and measurement in critically ill patients. J Parenter Enteral Nutr. 2013;37:705-13.

37. Elia M. Insights into energy requirements in disease. Public Health Nutr. 2005;8:1037-52.

\section{Submit your next manuscript to BioMed Central and take full advantage of:}

- Convenient online submission

- Thorough peer review

- No space constraints or color figure charges

- Immediate publication on acceptance

- Inclusion in PubMed, CAS, Scopus and Google Scholar

- Research which is freely available for redistribution 